\title{
Non-Teaching Staff Performance Analysis Using Multi-Criteria Group Decision Making Approach
}

\author{
Sukarna Dey ${ }^{1}$ and DipendraNath Ghosh ${ }^{2}$ \\ ${ }^{1,2}$ Department of Mathematics \\ Dr. B.C Roy Engineering College, Jemua Road, Fuljhore, Durgapur-713206 \\ West Bengal, India \\ ${ }^{1}$ sukarna.dey@bcrec.ac.in, 2dipen.ghosh@bcrec.ac.in
}

\begin{abstract}
The major assets of an education sector are manpower, money, machine and time. The manpower, while serving as the major driver of the other assets have three components, namely academic staff, administrative staff and non-teaching staff. It is proven that the poor management of the non-teaching staff often leads to the poor procurement and management of other assets. The rapid expansion of higher education has considerable impact on the quality of education. One of the most important issues impacting it is "nonteaching staff quality". The quality of education is primarily determined by the competences, skills, abilities along with motivation of non-teaching staff. Quality assessment refers to the examination and evaluation of employee's work via predetermined standards and procedures to assess his committee men to the post, the individual capability and performance [1].Various methods of appraisal have been used based on the management practices and the theoretical categorization of them. The most commonly applied methods are Balanced Scorecard (BSC), 360 Degree Appraisal, Management by Objectives (MBO) and Key Performance Indicators (KPI) [2].Currently, quality analyzes majority of the universities still consist of the conventional annual work report and the assessment after a tenure is completed, which is generally a quantifiable description of an academic staff's teaching and research work. The deficiency of such a method lies in a lack of overall assessment of the staff's performance; therefore it is one of the great significance to design a new mathematical model to analyze the performance of a non-teaching staff based on the existing information system while giving full consideration of several Experts' opinion. The system is characterized by the scientifically designed criteria using multi-criteria decision making to analyze the performance of a non-teaching staff with the help of eight methodologies containing AHP, COPRAS, SAW, TOPSIS, Fuzzy TOPSIS, PROMETHEE-2, Compromise Programming and Weighted Average, comparing the results and finally determines the rank using group decision making method.
\end{abstract}

Keywords: MCDM, AHP, COPRAS, SAW, TOPSIS, FTOPSIS, Promethee-2, Compromise Programming, Weighted Average, Spearman's Rank Correlation Coefficient and Group Decision Making

\section{Introduction}

According to Moon et al., [3], performance appraisal of candidates in relation to a particular position is a key task towards managing the human resources of an organization. Supervisors are concerned with performance appraisal judgments and evaluations that they have to make on their subordinates. On the other hand, subordinates are increasingly realizing the importance of performance analysis since it would be very much affected on their rewards and future career path. As the world began to shift towards knowledge based capitalism, it reminds all organizations on the importance of 
maintaining their talented knowledge workers [3]. Therefore, discovering and promoting the most qualified candidates is essential because valuable human expertise is the main source of competitive advantages for the organizations. Thus, qualification, subject knowledge, communication skill, past experience, negative activity, leadership \& managing power and mental stress are the important requirements towards performance analyzing of non-teaching staff. Multi Criteria Decision Making Approach provides better idea to analyze the performance of a non-teaching staff education sector. Pairwise comparison method like Analytical Hierarchy Process (AHP) developed by Saaty [4, 5] in 1980 is very useful to compare the different criterions and the alternatives selection of best candidate for non-teaching staff in education sector. The researchers of Vilnius Gediminas Technical University (Zavadskas, Kaklauskas 1996) has created a method of complex proportional evaluation COPRAS (Complex Proportional Assessment) in 1996. SAW method firstly practically used by Hwang and Yoon in 1981. Technique for Order Preference by Similarity to the Ideal Solution (TOPSIS) was first developed by Hwang and Yoon [6], is based on the idea that the chosen alternative should have the shortest distance from the positive ideal solution and on the other side the farthest distance of the negative ideal solution. Kazem Oraee and et. al., combined AHP with TOPSIS and PROMETHEE-2 in two step methodology for selecting a tunnel system [7]. Compromise Programming (CP) defines the best/suitable solution whose point is at the least from an ideal point (Zeleny, 1982; Gershon and duckstein et al., 1983; Duckstein et al., 1994).

The study is organized as follows: Section 2 emphases about the Experts' opinion, Section 3 focuses about MCDM approaches using eight methodologies for ranking the interview candidates on the basis of some experts' opinion followed by the comparison between the results and Section 4, 5 describes the final ranking by group decision analysis method. At the end of the paper in Section 6 concludes the same. This proposed methodology is effectively more powerful than the traditional methods.

\section{Experts' Opinion}

In this investigation, the proposed method is applied to analyze the performance of non-teaching staff of an education sector. Seven non-teaching staff were examined and randomly selected for the present study. A set of questionnaire is given by Experts'(E1, E2, E3),considering their individual judgment for each non-teaching staff on the basis of, qualification(C1), subject knowledge(C2), communication skill(C3), past experience $(\mathrm{C} 4)$, negative activity(C5), leadership \& managing power(C6) and mental stress(C7)which is presented in the Table 1.

Table 1. Experts Opinion against each Non Teaching Staff

\begin{tabular}{|c|c|c|c|c|c|c|c|c|c|c|c|c|c|c|c|}
\hline Criteria & \multicolumn{3}{|c|}{ C1 } & \multicolumn{3}{|c|}{$\mathrm{C} 2$} & \multicolumn{3}{|c|}{ C3 } & \multicolumn{3}{|c|}{$\mathrm{C4}$} & \multicolumn{3}{|c|}{ C5 } \\
\hline Types & \multicolumn{3}{|c|}{ Max } & \multicolumn{3}{|c|}{ Max } & \multicolumn{3}{|c|}{ Max } & \multicolumn{3}{|c|}{ Max } & \multicolumn{3}{|c|}{ Min } \\
\hline Staffs & E1 & E2 & E3 & E1 & E2 & E3 & E1 & E2 & E3 & E1 & E2 & E3 & E1 & E2 & $\mathbf{E 3}$ \\
\hline A1 & $\mathrm{g}$ & $\mathrm{vg}$ & $\mathrm{vg}$ & $\mathrm{b}$ & $\mathrm{g}$ & $\mathrm{b}$ & $\mathrm{e}$ & $\mathrm{vg}$ & $\mathrm{vg}$ & $\mathrm{g}$ & $\mathrm{b}$ & $\mathrm{a}$ & $\mathrm{vg}$ & $\mathrm{vg}$ & $\mathrm{e}$ \\
\hline $\mathrm{A} 2$ & $\mathrm{vg}$ & $\mathrm{vg}$ & $\mathrm{e}$ & $\mathrm{g}$ & $\mathrm{e}$ & $\mathrm{g}$ & $\mathrm{g}$ & $\mathrm{a}$ & $\mathrm{e}$ & $\mathrm{g}$ & $\mathrm{vg}$ & $\mathrm{vg}$ & $\mathrm{g}$ & $\mathrm{vg}$ & $\mathrm{vg}$ \\
\hline A3 & $\mathrm{e}$ & $\mathrm{e}$ & $\mathrm{g}$ & $\mathrm{vg}$ & $\mathrm{g}$ & $\mathrm{vg}$ & $\mathrm{e}$ & $\mathrm{e}$ & $\mathrm{e}$ & $\mathrm{vg}$ & $\mathrm{vg}$ & $\mathrm{g}$ & $\mathrm{g}$ & $\mathrm{e}$ & $\mathrm{e}$ \\
\hline A4 & $\mathrm{e}$ & $\mathrm{vg}$ & $\mathrm{vg}$ & $\mathrm{g}$ & $\mathrm{b}$ & $\mathrm{vg}$ & $\mathrm{b}$ & $\mathrm{g}$ & $\mathrm{e}$ & $\mathrm{b}$ & $\mathrm{g}$ & $\mathrm{a}$ & $\mathrm{e}$ & $\mathrm{g}$ & $\mathrm{g}$ \\
\hline A5 & $\mathrm{e}$ & $\mathrm{g}$ & $\mathrm{g}$ & $\mathrm{a}$ & $\mathrm{b}$ & $\mathrm{vg}$ & $\mathrm{g}$ & $\mathrm{a}$ & $\mathrm{vg}$ & $\mathrm{a}$ & $\mathrm{g}$ & $\mathrm{b}$ & $\mathrm{b}$ & $\mathrm{vg}$ & $\mathrm{e}$ \\
\hline A6 & $\mathrm{vg}$ & $\mathrm{g}$ & $\mathrm{vg}$ & $\mathrm{vg}$ & $\mathrm{g}$ & $\mathrm{g}$ & $\mathrm{e}$ & $\mathrm{a}$ & $\mathrm{vg}$ & $\mathrm{a}$ & $\mathrm{b}$ & $\mathrm{g}$ & $\mathrm{b}$ & $\mathrm{g}$ & $\mathrm{vg}$ \\
\hline A7 & $\mathrm{g}$ & $\mathrm{g}$ & $\mathrm{vg}$ & $\mathrm{g}$ & $\mathrm{g}$ & $\mathrm{b}$ & $\mathrm{b}$ & $\mathrm{a}$ & $\mathrm{vg}$ & $\mathrm{vg}$ & $\mathrm{e}$ & $\mathrm{a}$ & $\mathrm{e}$ & $\mathrm{g}$ & $\mathrm{g}$ \\
\hline Criteria & \multicolumn{3}{|c|}{ C6 } & \multicolumn{3}{|c|}{$\mathrm{C} 7$} & & & & & & & & & \\
\hline Types & \multicolumn{3}{|c|}{ Max } & \multicolumn{3}{|c|}{ Min } & & & & & & & & & \\
\hline Staffs & E1 & E2 & E3 & E1 & E2 & E3 & & & & & & & & & \\
\hline A1 & $\mathrm{vg}$ & $\mathrm{g}$ & $\mathrm{e}$ & $\mathrm{g}$ & $\mathrm{vg}$ & $\mathrm{g}$ & & & & & & & & & \\
\hline A2 & $\mathrm{g}$ & $\mathrm{b}$ & $\mathrm{e}$ & $\mathrm{a}$ & $\mathrm{b}$ & $\mathrm{g}$ & & & & & & & & & \\
\hline A3 & $\mathrm{b}$ & $\mathrm{g}$ & $\mathrm{g}$ & $\mathrm{b}$ & $\mathrm{g}$ & $\mathrm{g}$ & & & & & & & & & \\
\hline A4 & $\mathrm{e}$ & $\mathrm{vg}$ & $\mathrm{g}$ & $\mathrm{g}$ & $\mathrm{g}$ & $\mathrm{b}$ & & & & & & & & & \\
\hline A5 & $\mathrm{a}$ & $\mathrm{e}$ & $\mathrm{g}$ & $\mathrm{a}$ & $\mathrm{vg}$ & $\mathrm{e}$ & & & & & & & & & \\
\hline A6 & $\mathrm{g}$ & $\mathrm{g}$ & $\mathrm{vg}$ & $\mathrm{vg}$ & $\mathrm{a}$ & $\mathrm{a}$ & & & & & & & & & \\
\hline A7 & $\mathrm{vg}$ & $\mathrm{g}$ & $\mathrm{g}$ & $\mathrm{vg}$ & $\mathrm{a}$ & $\mathrm{g}$ & & & & & & & & & \\
\hline
\end{tabular}




\section{MCDM Approaches}

\subsection{Analytical Hierarchy Process}

It is one of the excellent and most extensively used MCDM approaches. AHP is an approach on decision making that involves structuring multiple choice criteria into a hierarchy, assessing the relative importance of these criteria comparing alternatives for each criterion and determining an overall ranking of the alternatives. Chang (1996) employed Triangular Fuzzy Numbers for the formulation of pairwise comparison matrix for a hypothetical problem and used synthetic extent methodology for ranking alternatives.

\section{Table 2. Saaty's 9-point Scale of Pair-Wise Comparison}

\begin{tabular}{|c|c|}
\hline Scale & Compare factor of $\mathbf{i}$ and $\mathbf{j}$ \\
\hline 1 & Equally Important \\
\hline 3 & Weakly Important \\
\hline 5 & Strongly Important \\
\hline 7 & Very Strongly Important \\
\hline 9 & Extremely Important \\
\hline $2,4,6,8$ & $\begin{array}{c}\text { Intermediate value betweenadjacent } \\
\text { scales }\end{array}$ \\
\hline
\end{tabular}

Table 3. Table of Random Index (Saaty, 1980)

\begin{tabular}{|c|c|c|c|c|c|c|c|c|c|c|c|c|}
\hline Matrix Order & 1,2 & 3 & 4 & 5 & 6 & 7 & 8 & 9 & 10 & 11 & 12 & 13 \\
\hline R.I & 0 & 0.52 & 0.89 & 1.12 & 1.26 & 1.36 & 1.41 & 1.46 & 1.49 & 1.52 & 1.54 & 1.56 \\
\hline
\end{tabular}

An AHP hierarchy has at least three levels:

Level 1: The main objective or goal of the problem at the beginning.

Level 2: Multiple criteria that define alternatives in the middle.

Level 3: Competing alternatives at the end.

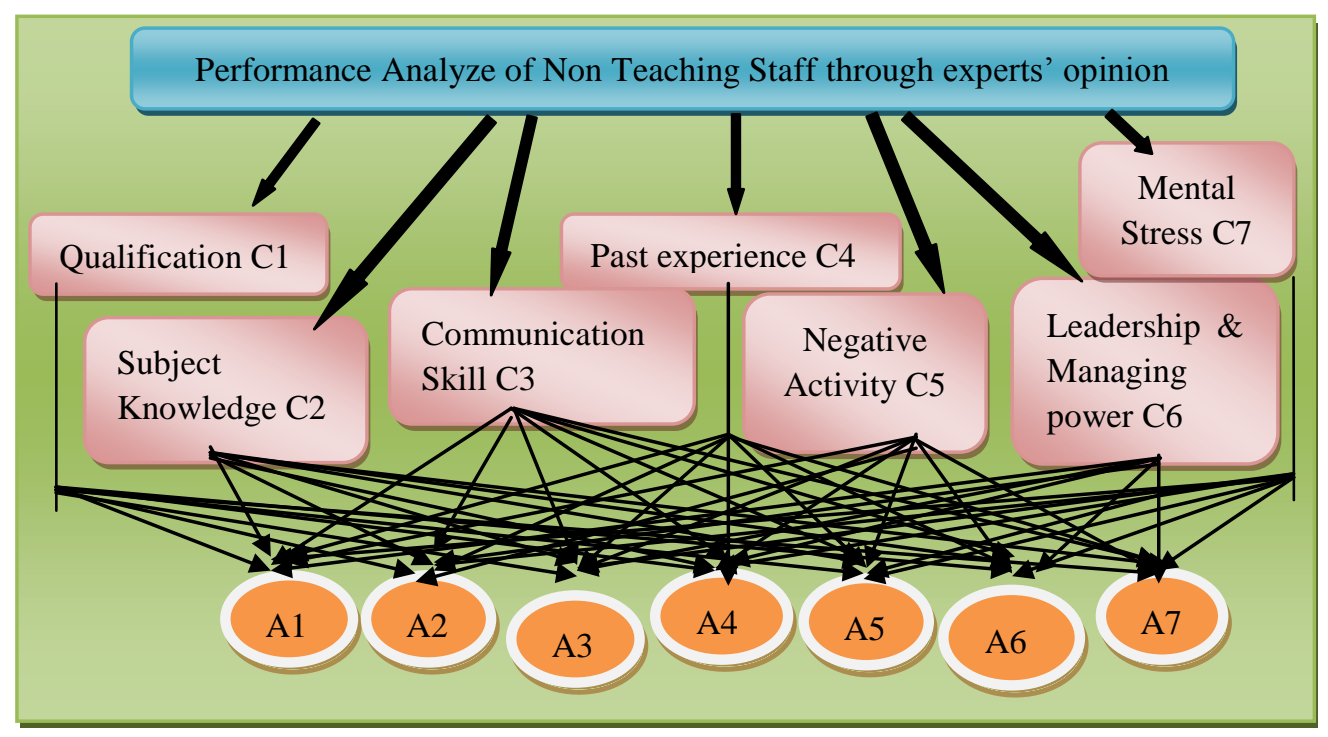

Figure 1. Hierarchy of Performance Analyze of Non-Teaching Staff 
The steps for implementing the AHP process are illustrated as follows:

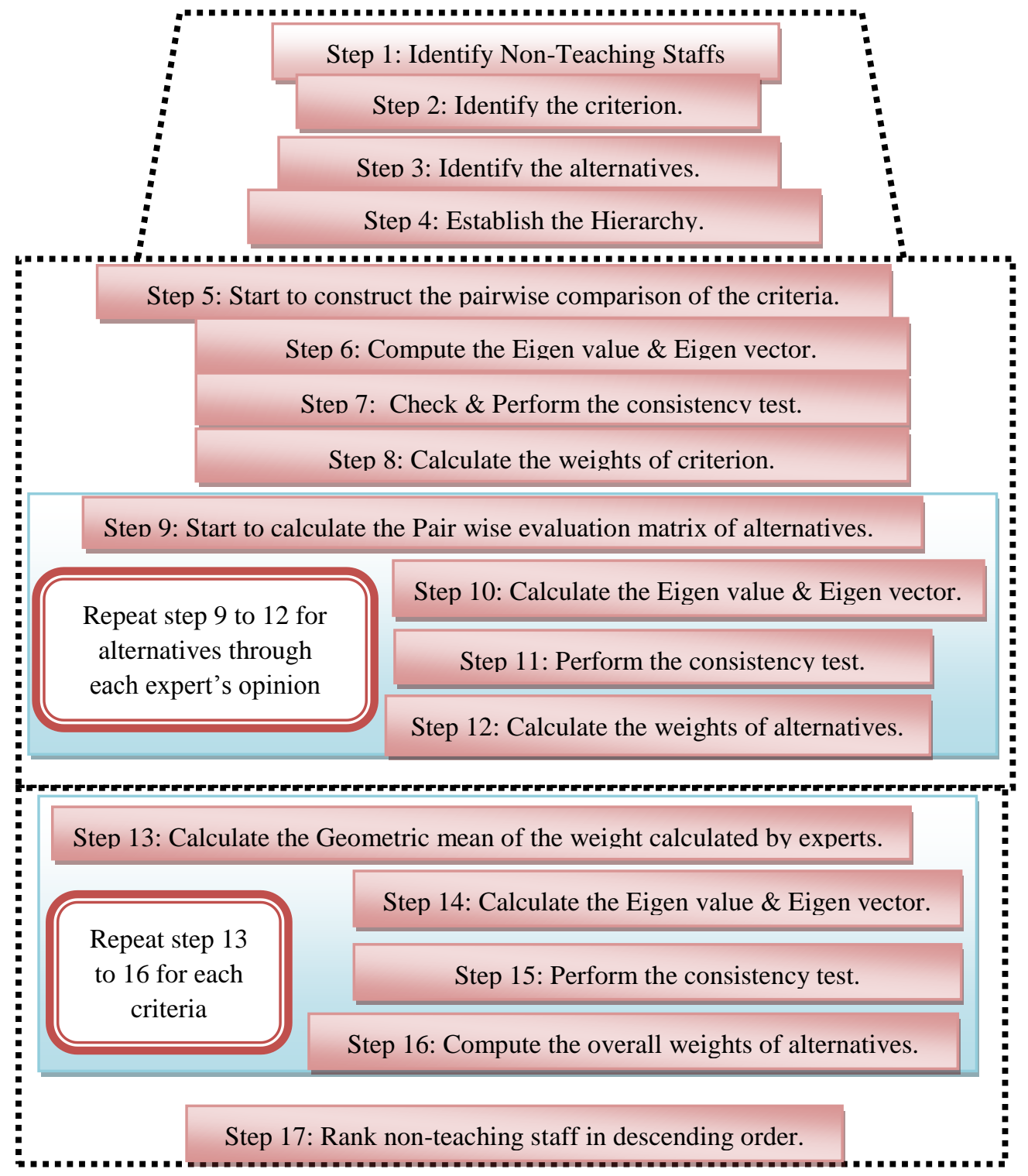

Figure 2. Steps of AHP Methodology

Table 4. Overall Weight of each Non-Teaching Staff by AHP Methodology

\begin{tabular}{|c|c|c|c|c|c|c|c|c|c|}
\hline Weight & $\mathbf{0 . 3 1 6 4}$ & $\mathbf{0 . 1 9 2 3}$ & $\mathbf{0 . 1 1 9 3}$ & $\mathbf{0 . 0 9 7 6}$ & $\mathbf{0 . 0 7 5 6}$ & $\mathbf{0 . 1 5 9 8 6}$ & $\mathbf{0 . 0 3 8 5}$ & $\begin{array}{l}\text { Global } \\
\text { Overall } \\
\text { utility }\end{array}$ & Rank \\
\hline Staffs & $\mathbf{C 1}$ & $\mathbf{C 2}$ & $\mathbf{C 3}$ & $\mathbf{C 4}$ & $\mathbf{C 5}$ & $\mathbf{C 6}$ & $\mathbf{C 7}$ & $\mathbf{4}$ \\
\hline $\mathbf{A 1}$ & 0.1227 & 0.0711 & 0.1893 & 0.1063 & 0.1664 & 0.1972 & 0.1886 & 0.1368 & $\mathbf{4}$ \\
\hline $\mathbf{A 2}$ & 0.1822 & 0.1877 & 0.1220 & 0.2158 & 0.1389 & 0.1195 & 0.0909 & 0.1625 & $\mathbf{2}$ \\
\hline $\mathbf{A 3}$ & 0.1772 & 0.2006 & 0.2744 & 0.2217 & 0.1850 & 0.0821 & 0.1105 & 0.1804 & $\mathbf{1}$ \\
\hline $\mathbf{A 4}$ & 0.1819 & 0.1171 & 0.1122 & 0.0869 & 0.1313 & 0.1937 & 0.1105 & 0.1471 & $\mathbf{3}$ \\
\hline A5 & 0.1178 & 0.0842 & 0.0969 & 0.0842 & 0.1441 & 0.1350 & 0.2151 & 0.1140 & 7 \\
\hline A6 & 0.1194 & 0.1661 & 0.1320 & 0.0931 & 0.0939 & 0.1376 & 0.1282 & 0.1286 & $\mathbf{6}$ \\
\hline A7 & 0.0988 & 0.1732 & 0.0731 & 0.1921 & 0.1404 & 0.1349 & 0.1562 & 0.1303 & $\mathbf{5}$ \\
\hline
\end{tabular}




\subsection{Complex Proportional Assessment (COPRAS)}

A single criterion cannot give a full expression of the goals pursued by various clients. For this purpose, multi-attribute decision method COPRAS can be used. In 1996, the researchers of Vilnius Gediminas Technical University (Zavadskas, Kaklauskas 1996) had created a method of complex proportional evaluation COPRAS (Complex Proportional Assessment). It is used for multi criteria evaluation of both maximizing and minimizing criteria values. This is the advantage of the method COPRAS over the SAW method. In order to evaluate the overall efficiency of a project it is necessary to identify selection attributes, to assess information relating to these attributes, and to develop methods for evaluating the attributes to meet the participant's needs. Decision analysis is concerned with situation in which decision makers have to choose among the several alternatives through the consideration of a common set of attributes. The COPRAS method (Zavadskas and Kaklauskas, 1996) presented here, uses a stepwise ranking and evaluating procedure of the alternatives in terms of significance and utility degree. This method was applied to the solution of various problems in construction, property management, economics, and etc. (Zavadskas et al., 2007 and etc.). In this method, the influence of maximizing and minimizing criteria on the evaluation result is considered separately.

The steps for implementing the COPRAS process are illustrated as follows:

Step 1: Calculate weighted normalized decision matrix using the table 1.

Step 2: Sums of attributes values where larger values are more preferable (optimization direction is maximization) calculation for each alternative.

Step 3: Sums of attributes values which are have smaller values are more preferable (optimization direction is minimization) calculation for each alternative.

Step 4: Determine the minimal value.

Step 5: Calculate of the relative weight of each alternative.

Step 6: Determine of the optimality criterion.

Step 7: Determine of the priority of the project.

Step 8: Calculate of the utility degree of each alternative.

Step 9: Rank non-teaching staffs in descending order.

Figure 3. Steps of COPRAS Methodology

Table 5. Ranking of Non Teaching Staffs using COPRAS Method Obtaining from Table 4

\begin{tabular}{|c|c|c|c|c|c|}
\hline Staffs & $\mathbf{S}_{\mathbf{+}}$ & $\mathbf{S}_{\mathbf{}_{\mathbf{j}}}$ & $\mathbf{1}_{\mathbf{S}} \mathbf{-}_{\mathbf{i}}$ & $\mathbf{Z}_{\mathbf{i}}$ & Rank \\
\hline $\mathbf{A 1}$ & 0.116987 & 0.019856 & 50.36322 & 0.129991 & $\mathbf{5}$ \\
\hline $\mathbf{A 2}$ & 0.148472 & 0.014009 & 71.38097 & 0.166902 & $\mathbf{2}$ \\
\hline $\mathbf{A 3}$ & 0.162157 & 0.018251 & 54.7901 & 0.176304 & $\mathbf{1}$ \\
\hline $\mathbf{A 4}$ & 0.132908 & 0.01419 & 70.4712 & 0.151103 & $\mathbf{3}$ \\
\hline $\mathbf{A 5}$ & 0.094828 & 0.019191 & 52.10806 & 0.108282 & $\mathbf{7}$ \\
\hline $\mathbf{A 6}$ & 0.11656 & 0.012044 & 83.0285 & 0.137997 & $\mathbf{4}$ \\
\hline $\mathbf{A 7}$ & 0.113611 & 0.01664 & 60.09511 & 0.129127 & $\mathbf{6}$ \\
\hline
\end{tabular}




\subsection{Simple Additive Weighting (SAW)}

SAW is the oldest, most widely known and practically used method (Hwang, Yoon 1981; Chu et al., 2007; Ginevicius, Podvezko 2008 a,b,c; Ginevicius et al., 2008c; Podvezko 2008; Ginevicius, Gineviciene 2009; Zavadskas et al., 2007c; Jakimavicius, Burinskiene 2009; Podvezko et al., 2010; Sivilevicius et al. 2008). The criterion of the method $S j$ clearly demonstrates the main concept of multi criteria evaluation methods the integration of the criteria values and weights into a single magnitude. The method is based on the weighted average. An evaluation score is calculated for each alternative by multiplying the scaled value given to the alternative of that attribute with the weights of relative importance directly assigned by decision maker followed by summing of the products for all criteria. The advantage of this method is that it is a proportional linear transformation of the raw data which means that the relative order of magnitude of the standardized scores remains equal.

The steps for implementing the SAW process are illustrated as follows:

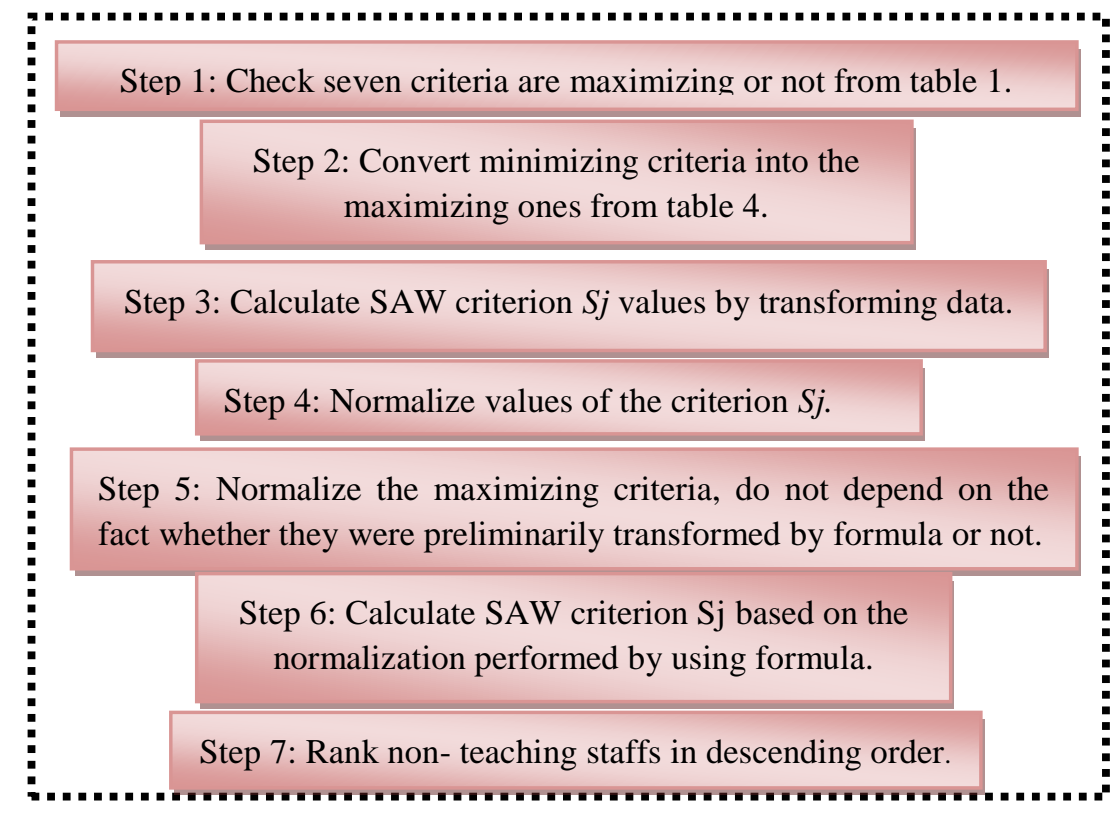

Figure 4. Steps of SAW Methodology

Table 6. Ranking of Non-Teaching Staffs using SAW Method Obtaining from Table 4

\begin{tabular}{|c|c|c|}
\hline Staffs & $\mathbf{S}_{\mathbf{j}}$ & Rank \\
\hline A1 & 0.12974777 & $\mathbf{5}$ \\
\hline A2 & 0.167124323 & $\mathbf{2}$ \\
\hline A3 & 0.176733807 & $\mathbf{1}$ \\
\hline A4 & 0.152660223 & $\mathbf{3}$ \\
\hline A5 & 0.108496018 & 7 \\
\hline A6 & 0.138017172 & $\mathbf{4}$ \\
\hline A7 & 0.128819403 & $\mathbf{6}$ \\
\hline
\end{tabular}

\subsection{Technique for Order Preference by Similarity to the Ideal Solution (TOPSIS)}

TOPSIS is based on the principle that the chosen alternative should have the shortest distance from the ideal solution and farthest solution from the negative ideal solution (Chen and Hwang, 1992; Opricovic and Tzeng, 2004). It was first developed by Hwang 
and Yoon [6]. In the process of TOPSIS, the performance ratings and the weights of the criteria are given as exact values. Abo-sinna and Amer [8] extend TOPSIS approach to solve multi-objective nonlinear programming problems. Jahanshahloo et al., [9] extend the concept of TOPSIS to develop a methodology for solving multi-criteria decisionmaking problems with interval data.

The steps for implementing the TOPSIS process are illustrated as follows:

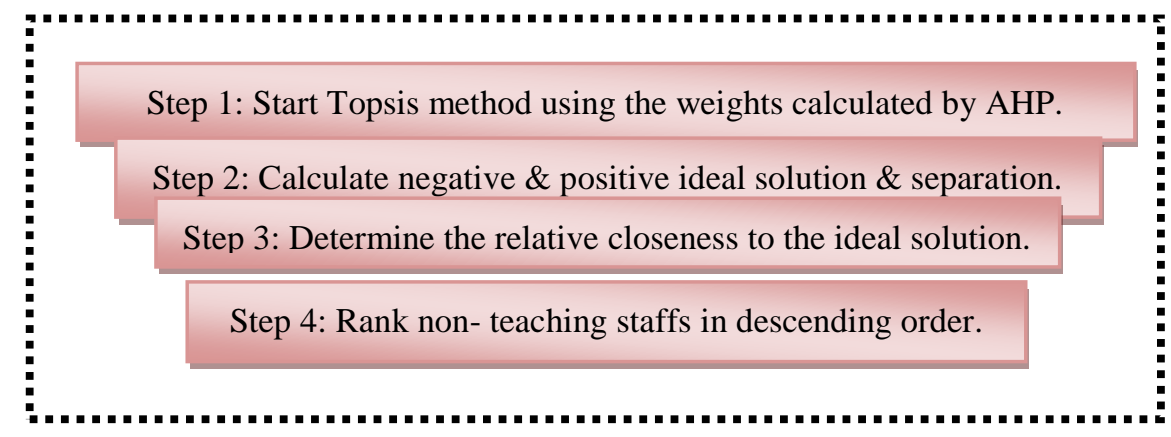

Figure 5. Steps of TOPSIS Methodology

\section{Table 7. Ranking of Non-Teaching Staffs using TOPSIS Method Obtaining from Table 4}

\begin{tabular}{|r|c|c|c|c|}
\hline Staffs & $\mathbf{D}_{\mathbf{a}}{ }^{+}$ & $\mathbf{D}_{\mathbf{a}}{ }^{-}$ & $\mathbf{C}_{\mathbf{a}}$ & Rank \\
\hline $\mathbf{A 1}$ & 0.087401 & 0.063595 & 0.421169 & $\mathbf{4}$ \\
\hline $\mathbf{A 2}$ & 0.056724 & 0.096358 & 0.629456 & $\mathbf{2}$ \\
\hline $\mathbf{A 3}$ & 0.048346 & 0.113003 & 0.700366 & $\mathbf{1}$ \\
\hline $\mathbf{A 4}$ & 0.071213 & 0.085731 & 0.546255 & $\mathbf{3}$ \\
\hline $\mathbf{A 5}$ & 0.10162 & 0.032253 & 0.240925 & $\mathbf{7}$ \\
\hline $\mathbf{A 6}$ & 0.08074 & 0.056614 & 0.412178 & $\mathbf{5}$ \\
\hline $\mathbf{A 7}$ & 0.09479 & 0.06067 & 0.390261 & $\mathbf{6}$ \\
\hline
\end{tabular}

\subsection{Concept of Fuzzy TOPSIS}

3.5.1. Fuzzy Sets: A fuzzy set is a class of objects with a range of grades of membership. A membership function characterizes such a set which assigns to each object a grade of membership ranging between zero and one [10, 11]. Fuzzy logic is a powerful mathematical tool for representing uncertainty in every field. Their role is significant when applied to complex phenomena which are not easily described by traditional mathematical methods, especially when the goal is to find a good approximation solution [7]. Fuzzy sets have proven to be an eminent way for solving the decision problems where the information available is subjective and vague [12-14].

3.5.2. Linguistic Variable: A variable which can be a word or a sentence in a natural or artificial language is often referred to as linguistic variable [15]. For example, marks can be a linguistic variable if they are assumed to be the fuzzy variables labeled very good, good, bad, very bad etc rather than numbers $0,1,2,3,4 \ldots$ For some situations where the evaluation becomes too complex and conventional quantitative terms cannot be used, linguistic variables can provide a means of approximate characterization of the phenomena. The main applications of the linguistic approach lie especially in the fields of artificial intelligence, linguistics, human decision processes, pattern recognition, psychology, law, medical diagnosis, information retrieval, economics and related areas [15]. 
3.5.3. Fuzzy Numbers: A fuzzy number $\tilde{M}$ is a convex normalized fuzzy set $\tilde{M}$ of the real line $\mathrm{R}$ which exists [12] such that one $x_{o} \in \mathrm{R}$ with $\mu_{\hat{M}}\left(x_{o}\right)=1$ ( $x_{o}$ is called mean value of $\tilde{M}$ ) and $\mu_{\hat{M}}\left(x_{0}\right)$ is piecewise continuous. Triangular fuzzy numbers (TFNs) are often convenient to work with because of their computational simplicity, and they are useful in representation and information processing in a fuzzy environment. In this study TFNs are adopted in the fuzzy AHP method. TFNs can be defined as a triplet $(1, \mathrm{~m}, \mathrm{u})$. The parameters $1, \mathrm{~m}, \mathrm{u}$ indicate the smallest possible value, the most promising value, and the largest possible value that describes a fuzzy event. A triangular fuzzy number $\tilde{M}$ is shown in Figure 6:

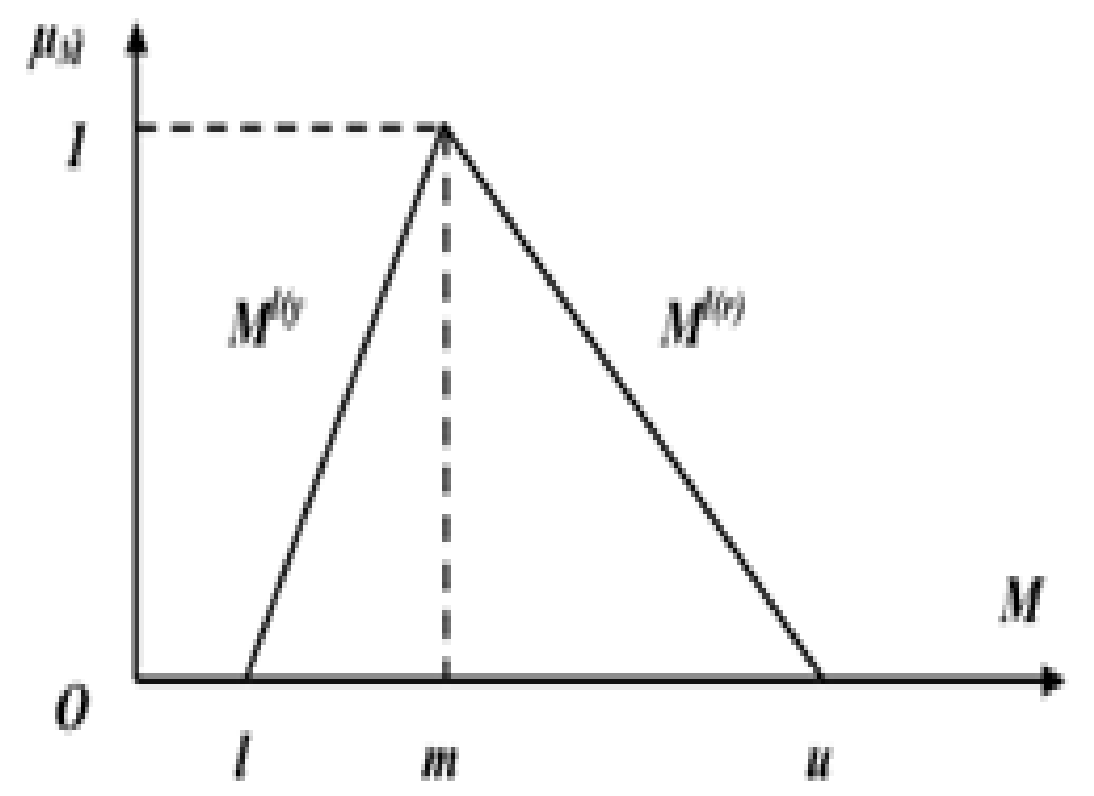

Figure 6. Triangular Fuzzy Number

3.5.4. Fuzzy TOPSIS: In the classical TOPSIS method, the weights of the criteria and the ratings of alternatives are known precisely and crisp values are used in the evaluation process. However, under many conditions crisp data are inadequate to model real-life decision problems. In addition to that, perfect knowledge is not easily acquired. Unquantifiable, incomplete and non-obtainable information [16] make precise Judgment impossible. Therefore, the Fuzzy TOPSIS [17] method is proposed for our work where the weights of criteria and ratings of alternatives are evaluated by linguistic variables represented by fuzzy numbers to deal with the deficiency in the traditional TOPSIS. Triantaphyllou and Lin [18] developed a fuzzy version of the TOPSIS method based on fuzzy arithmetic operations, which leads to a fuzzy relative closeness for each alternative. 
The steps for implementing the Fuzzy TOPSIS process are illustrated as follows:

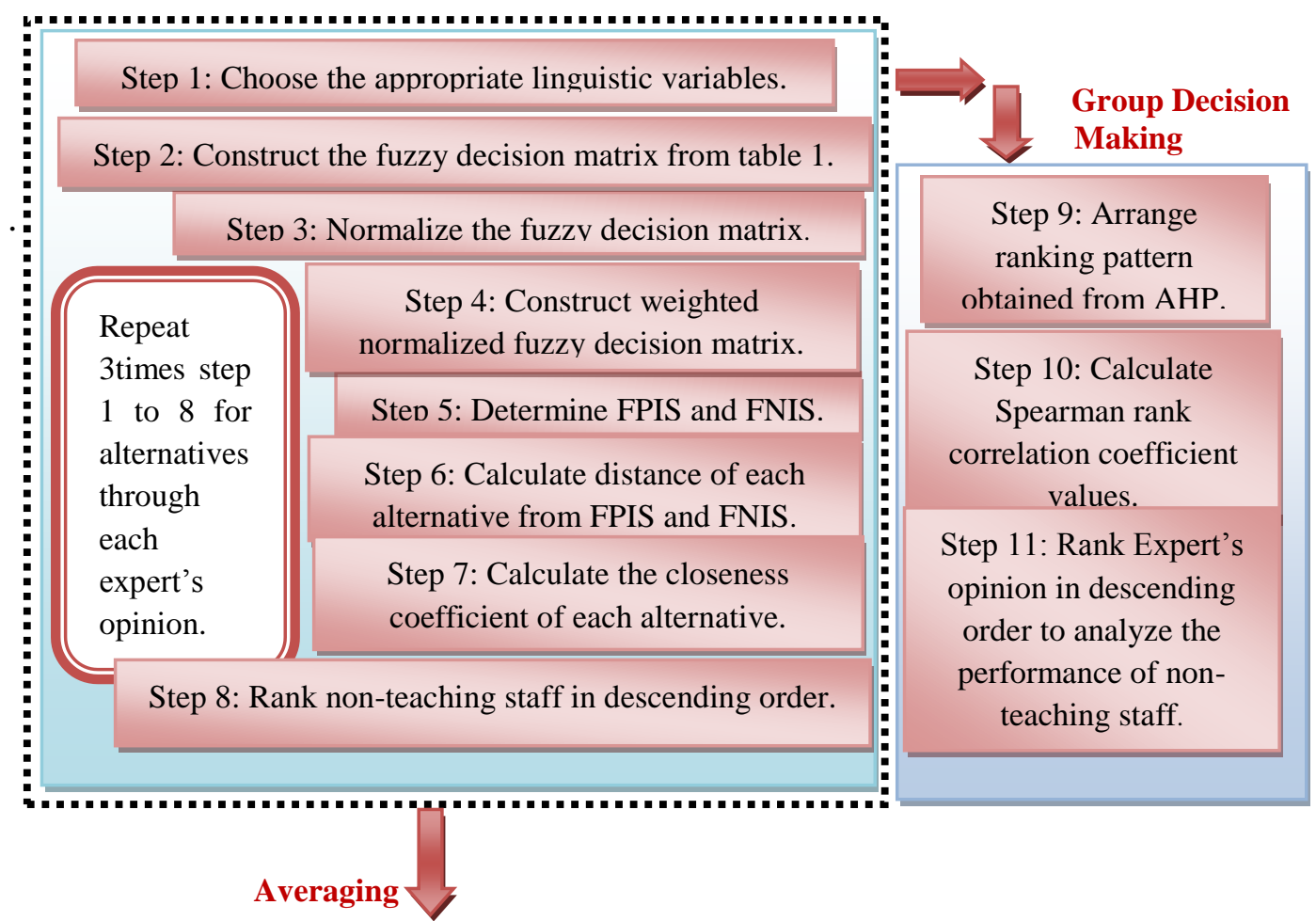

Step 9: Calculate the sum of closeness coefficient of three experts.

Step 10: Determine average of closeness coefficient.

Step 11: Rank non-teaching staffs in descending order.

Figure 7. Steps of Fuzzy TOPSIS Methodology

Table 8. Ranking of Non-Teaching Staffs using Fuzzy TOPSIS Method by Averaging Obtaining from Table 1

\begin{tabular}{|c|c|c|c|c|c|}
\hline \multirow{2}{*}{ Staffs } & \multicolumn{3}{|c|}{ Closeness Coefficient } & \multicolumn{2}{c|}{} \\
\cline { 2 - 4 } & $\begin{array}{c}\text { Ci (for } \\
\text { E1) }\end{array}$ & $\begin{array}{c}\text { Ci (for } \\
\text { E2) }\end{array}$ & $\begin{array}{c}\text { Ci (for } \\
\text { E3) }\end{array}$ & AVG & RANK \\
\hline $\mathbf{A 1}$ & 0.434903 & 0.451008 & 0.400244 & 0.4287183 & $\mathbf{5}$ \\
\hline $\mathbf{A 2}$ & 0.488198 & 0.461503 & 0.826354 & 0.5920183 & $\mathbf{2}$ \\
\hline $\mathbf{A 3}$ & 0.71348 & 0.700293 & 0.491371 & 0.635048 & $\mathbf{1}$ \\
\hline $\mathbf{A 4}$ & 0.651399 & 0.371568 & 0.484854 & 0.502607 & $\mathbf{3}$ \\
\hline $\mathbf{A 5}$ & 0.37811 & 0.317982 & 0.39187 & 0.362654 & $\mathbf{6}$ \\
\hline $\mathbf{A 6}$ & 0.605391 & 0.19472 & 0.492381 & 0.4308307 & $\mathbf{4}$ \\
\hline $\mathbf{A 7}$ & 0.496316 & 0.299686 & 0.19222 & 0.3294073 & $\mathbf{7}$ \\
\hline
\end{tabular}


It is noted from Table 10 that after using Group decision making (which will be discuss briefly at the end of the paper ) on Fuzzy TOPSIS, the ranking of Decisions makers are same which means their opinion is not biased on evaluating and they gave their fair judgments to analyze the performance for non-teaching staffs. That is the positive inference of this methodology.

Table 9. Ranking Pattern of Non-Teaching Staffs through Experts' Opinion

\begin{tabular}{|c|c|c|c|}
\hline Staffs & E1 & E2 & E3 \\
\hline A1 & 6 & 3 & 5 \\
\hline A2 & 5 & 2 & 1 \\
\hline A3 & 1 & 1 & 3 \\
\hline A4 & 2 & 4 & 4 \\
\hline A5 & 7 & 5 & 6 \\
\hline A6 & 3 & 7 & 2 \\
\hline A7 & 4 & 6 & 7 \\
\hline
\end{tabular}

Table 10. Ranking of Decision Makers using Group Decision Making

\begin{tabular}{|c|c|c|c|c|c|c|c|}
\hline $\begin{array}{l}\text { Decisi } \\
\text { on } \\
\text { Maker }\end{array}$ & E1 & E2 & E3 & SUM & $\begin{array}{c}\text { No of } \\
\text { considered } \\
\text { elements }\end{array}$ & Avg & $\begin{array}{c}\text { Rank of } \\
\text { Decision } \\
\text { Maker }\end{array}$ \\
\hline E1 & & & 0.357143 & 0.357143 & 1 & 0.35714 & $\mathbf{1}$ \\
\hline E2 & & & 0.357143 & 0.357143 & 1 & 0.35714 & $\mathbf{1}$ \\
\hline E3 & 0.357143 & 0.357143 & & 0.714286 & 2 & 0.35714 & $\mathbf{1}$ \\
\hline
\end{tabular}

\subsection{PROMETHEE-2}

PROMETHEE-2 (Preference Ranking Organization Method of Enrichment Evaluation) is a MCDM method of outranking nature. It is one among the 5 versions of PROMETHEE, i.e. 1 to $5[19,20]$. The method is based on preference function approach [21]. Thus it considers a preference between alternative individually. In this study, PROMETHEE-2 is used to obtain the final ranking from the weighted normalized matrix. The steps for implementing the PROMETHEE 2 process are illustrated as follows:

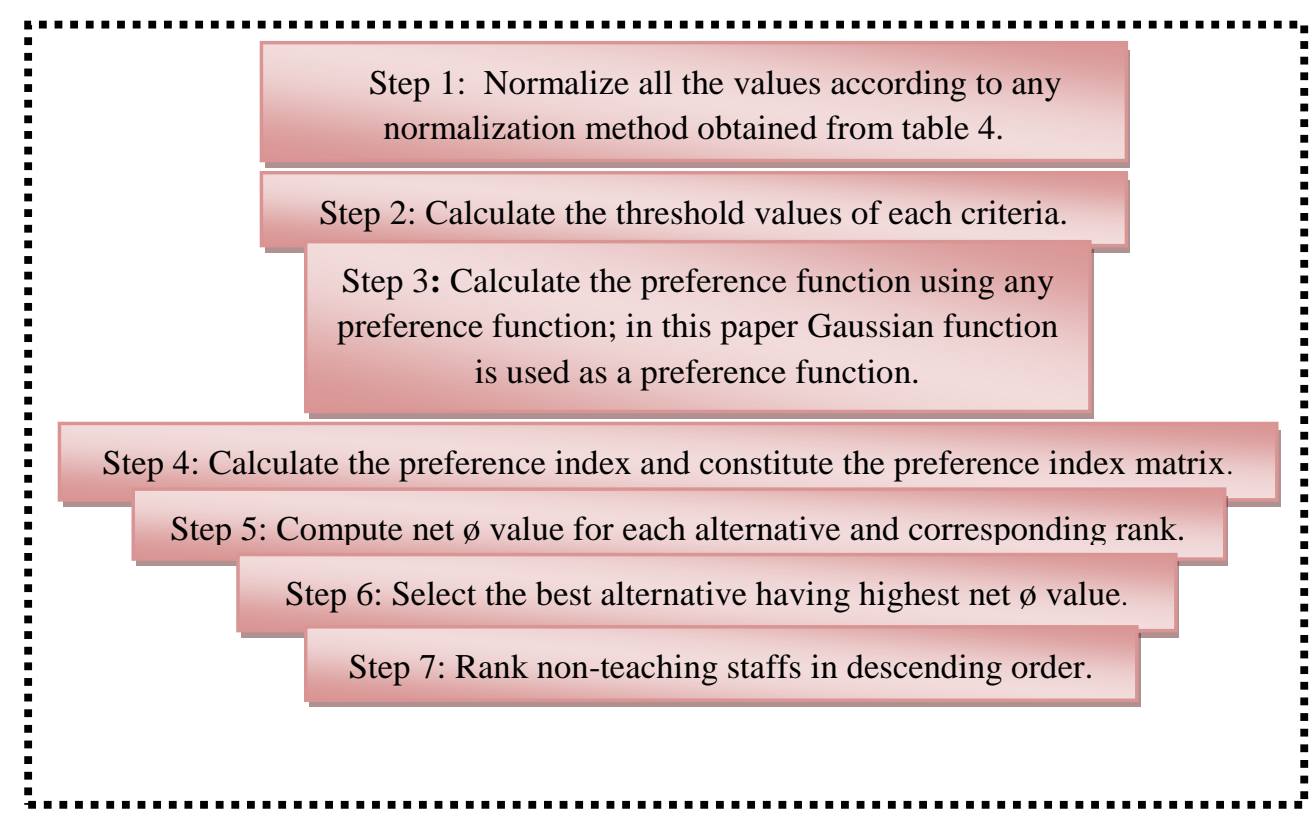

Figure 8. Steps of PROMETHEE-2 Methodology 


\section{Table 11. Ranking of Non-Teaching Staffs using PROMETHEE-2 Method} Obtaining from Table 4

\begin{tabular}{|c|c|c|c|c|}
\hline $\mathbf{N}$ & 7 & & & \\
\hline Staffs & $\Phi+$ & $\Phi-$ & $\Phi$ & Rank \\
\hline A1 & $3.85 \mathrm{E}-05$ & $6 \mathrm{E}-05$ & $-2.1 E-05$ & 4 \\
\hline A2 & 6.39E-05 & $2.35 \mathrm{E}-05$ & $4.05 \mathrm{E}-05$ & 2 \\
\hline A3 & 0.000133 & $2.25 \mathrm{E}-05$ & 0.000111 & 1 \\
\hline A4 & $3.91 \mathrm{E}-05$ & $4.47 \mathrm{E}-05$ & $-5.6 \mathrm{E}-06$ & 3 \\
\hline A5 & $1.02 \mathrm{E}-05$ & $7.81 \mathrm{E}-05$ & $-6.8 \mathrm{E}-05$ & 7 \\
\hline A6 & $1.69 \mathrm{E}-05$ & $4.82 \mathrm{E}-05$ & $-3.1 \mathrm{E}-05$ & 6 \\
\hline A7 & $3.14 \mathrm{E}-05$ & $5.62 \mathrm{E}-05$ & $-2.5 \mathrm{E}-05$ & 5 \\
\hline
\end{tabular}

\subsection{Compromise Programming}

Compromise Programming (CP) defines the best/suitable solution as the one in the set of efficient solutions whose point is at the least from an ideal point (Zeleny, 1982; Gershon and duckstein et al., 1983; Duckstein et al., 1994).The objective is to obtain a solution that is as 'close' as possible to some 'ideal' solution. The distance measure used in Compromise Programming (CP) is the family $\mathrm{L}_{\mathrm{p}}$-metrics. If the criteria are not expressed in commensurable terms, suitable normalization approach can be incorporated to ensure the same range/interval for each criterion, i.e., $[0,1]$.

For $\mathrm{p}=1$, all deviations are taken into account in direct proportion to their magnitude. For $\mathrm{p}=\infty$, the largest deviation is the only one taken into account corresponding to zero compensation between deviations.

The steps for implementing Compromise Programming process are illustrated as follows:

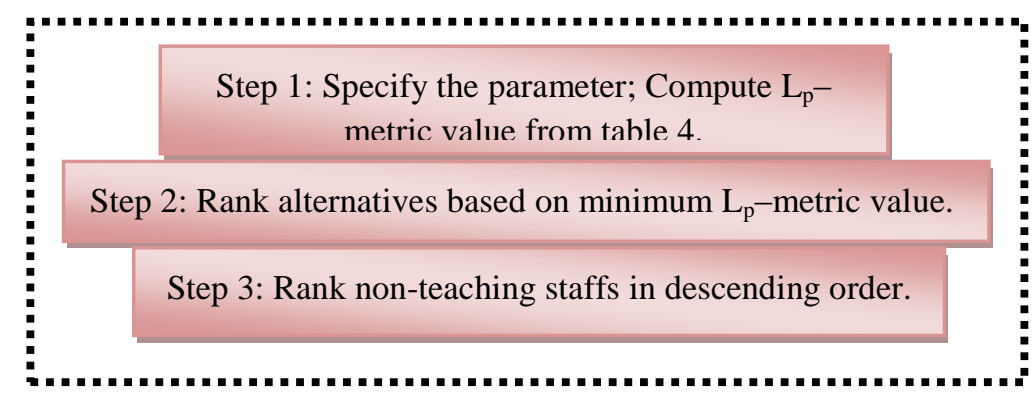

Figure 9. Steps of Compromise Programming Methodology

Table 12. Ranking of Non-Teaching Staffs using Compromise Programming Method Obtaining from Table 4

\begin{tabular}{|c|c|c|c|c|c|c|}
\hline Staffs & $\mathbf{P = 1}$ & Rank & $\mathbf{P = 2}$ & Rank & $\mathbf{P}=\infty$ & Rank \\
\hline A1 & 0.617461 & $\mathbf{5}$ & 0.286042 & $\mathbf{4}$ & 0.973719 & $\mathbf{4}$ \\
\hline A2 & 0.352124 & $\mathbf{1}$ & 0.191945 & $\mathbf{1}$ & 0.143123 & $\mathbf{1}$ \\
\hline A3 & 0.571157 & $\mathbf{3}$ & 0.27305 & $\mathbf{3}$ & 0.972899 & $\mathbf{3}$ \\
\hline A4 & 0.599552 & $\mathbf{4}$ & 0.319704 & $\mathbf{5}$ & 0.965789 & $\mathbf{2}$ \\
\hline A5 & 0.776388 & $\mathbf{6}$ & 0.342048 & $\mathbf{6}$ & 0.974254 & $\mathbf{5}$ \\
\hline A6 & 0.392134 & $\mathbf{2}$ & 0.21948 & $\mathbf{2}$ & 0.979639 & $\mathbf{7}$ \\
\hline A7 & 0.783163 & $\mathbf{7}$ & 0.393912 & $\mathbf{7}$ & 0.974465 & $\mathbf{6}$ \\
\hline
\end{tabular}




\subsection{Weighted Average Method}

Weighted Average Method is a utility type MCDM method. It is expressed as the average of the weighed sum of criterion values i.e., $U_{a}=w_{1} u_{1}+w_{2} u_{2}+\ldots \ldots . .+w_{j} u_{j}$ when $U_{a}$ is the overall utility value for alternative $a ; w_{1}, w_{2}, w_{3}, \ldots \ldots \ldots, w_{j}$ are the weights assigned to the criterion and $u_{1}, u_{2}, u_{3}, \ldots \ldots \ldots, u_{j}$ are the corresponding criteria values. The alternative having the highest overall utility is considered the best.

The steps for implementing Weighted Average Method process are illustrated as follows:

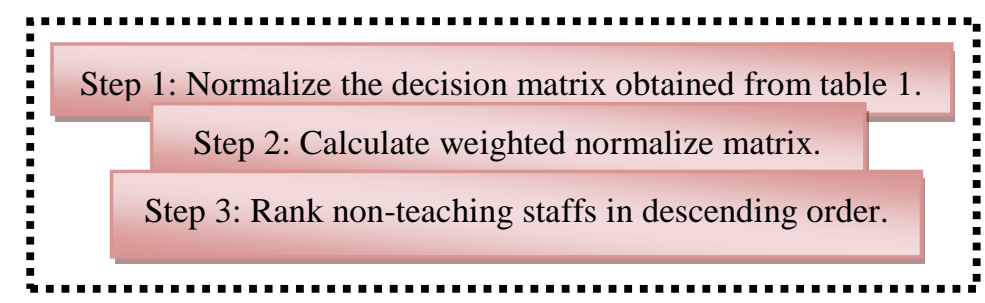

Figure 10. Steps of Weighted Average Methodology

\section{Table 13. Ranking of Non Teaching Staffs using Weighed Average Method Obtaining from Table 4}

\begin{tabular}{|c|c|c|c|c|c|c|c|c|c|}
\hline \multirow[b]{3}{*}{ Staffs } & 0.31636 & 0.19233 & 0.11934 & 0.09762 & 0.07562 & 0.15986 & 0.03855 & & \\
\hline & \multicolumn{7}{|c|}{ Criteria } & \multirow{2}{*}{$\begin{array}{l}\text { Weighted } \\
\text { Average } \\
\text { Value }\end{array}$} & \multirow[t]{2}{*}{ Rank } \\
\hline & C1 & $\mathrm{C} 2$ & $\mathrm{C} 3$ & $\mathrm{C} 4$ & C5 & C6 & C7 & & \\
\hline A1 & 0.31614 & 0.17835 & 0.45809 & 0.25994 & 0.43291 & 0.50450 & 0.47849 & 0.346205 & 4 \\
\hline A2 & 0.46944 & 0.47084 & 0.29523 & 0.52770 & 0.36137 & 0.30572 & 0.23062 & 0.4109199 & 2 \\
\hline A3 & 0.45656 & 0.50320 & 0.66403 & 0.54213 & 0.48130 & 0.2100 & 0.28034 & 0.4541810 & 1 \\
\hline A4 & 0.46867 & 0.29374 & 0.27151 & 0.21250 & 0.34159 & 0.49555 & 0.28034 & 0.3737799 & 3 \\
\hline A5 & 0.30351 & 0.21121 & 0.23449 & 0.20589 & 0.37489 & 0.34537 & 0.54573 & 0.2893363 & 7 \\
\hline A6 & 0.30764 & 0.41666 & 0.31943 & 0.22766 & 0.24429 & 0.35202 & 0.32525 & 0.3251023 & 6 \\
\hline A7 & 0.25456 & 0.43447 & 0.17689 & 0.46975 & 0.36527 & 0.34512 & 0.39629 & 0.3291437 & 5 \\
\hline
\end{tabular}

\section{Correlation Coefficients}

Multi-criteria Decision Making is required to assess the correlation/consistency between different ranking patterns obtained by different MCDM methods and/or different decision makers and/or different scenarios for a given set of alternatives forms a major part in their comparative study. Correlation coefficients measure the extent to which the ranks are correlated which can be used in this regard. These values vary from +1.00 (perfect positive relation) to -1.00 (perfect negative relationship) and value of zero indicates no relationship. A non-parametric rank correlation method namely, Spearman which is used to compute correlation coefficient values is explained as follows-

\subsection{Spearman Rank Correlation Method}

Spearman rank correlation coefficient $\rho$ is useful to determine the measure of association/correlation (including positive or negative direction of a relationship) between ranks achieved by different MCDM methods and/or different decision-makers and/or different scenarios for a given set of alternatives. If $U_{a}$ and $V_{a}$ denote the ranks achieved by above situation(s) for the same alternative a, then $\rho$ is defined as [22]: 


$$
\rho=1-\frac{6 \sum_{\alpha=1}^{n} d_{\alpha}^{2}}{n^{3}-n}
$$

Where $d_{a}=$ difference between ranks $U_{a}$ and $V_{a}$ achieved by the same alternative a $n=$ number of alternatives and $-1 \leq \rho \leq 1$.

Various critical values for Spearman rank correlation coefficient for various significance levels is provided in [23]. Numerous case studies have used the Spearman rank correlation method for computation of correlation coefficient values [24].

Characteristics of $\mathrm{R}$ can be explained in Table 11 as:

Table 14. Characteristics of Co-efficient $\mathbf{R}$

\begin{tabular}{|c|c|c|}
\hline Correlation & Nature of & Remark \\
\hline $\mathbf{0 . 9}-\mathbf{1 . 0}$ & Very High & Very Strong \\
\hline $\mathbf{0 . 7}-\mathbf{0 . 9}$ & High & Marked \\
\hline $\mathbf{0 . 4 - 0 . 7}$ & Moderate & Substantial \\
\hline $\mathbf{0 . 2}-\mathbf{0 . 4}$ & Low & Definite \\
\hline$<\mathbf{0 . 2}$ & Slight & Small \\
\hline
\end{tabular}

\section{Group Decision Making}

In case of individual decision-making (single decision-maker situation), the best alternative can be easily in accordance with the preference of the decision-maker. However when the decision is particularly complex in nature, with personal interests and conflicting preferences among a good number of decision-makers involved, which may lead to an unsatisfactory conclusion and sometimes may be even erroneous. In this regard, effective group decision-making can be viewed as a process in which individual interests are reduced and integrated so as to form a single group preference or consensus [25]. An integrated approach can be used where rank coefficient values can be used as a bench marks as to certain the conflicting nature of decision makers and their strength.

The steps for implementing Group Decision Making are illustrated as follows:

Step 1: Arrange ranking pattern obtained from seven methodologies.

Table 15. Ranking Pattern of Non-Teaching Staffs

\begin{tabular}{|c|c|c|c|c|c|c|c|c|}
\hline Staffs & AHP & Copras & SAW & Topsis & FTOPSIS & $\begin{array}{c}\text { Promethee- } \\
\mathbf{2}\end{array}$ & $\begin{array}{c}\text { Compromise } \\
\text { Programming }\end{array}$ & $\begin{array}{c}\text { Weighted } \\
\text { Avg }\end{array}$ \\
\hline A1 & $\mathbf{4}$ & $\mathbf{5}$ & $\mathbf{5}$ & $\mathbf{4}$ & $\mathbf{5}$ & $\mathbf{4}$ & $\mathbf{4}$ & $\mathbf{4}$ \\
\hline A2 & $\mathbf{2}$ & $\mathbf{2}$ & $\mathbf{2}$ & $\mathbf{2}$ & $\mathbf{2}$ & $\mathbf{2}$ & $\mathbf{1}$ & $\mathbf{2}$ \\
\hline A3 & $\mathbf{1}$ & $\mathbf{1}$ & $\mathbf{1}$ & $\mathbf{1}$ & $\mathbf{1}$ & $\mathbf{1}$ & $\mathbf{3}$ & $\mathbf{1}$ \\
\hline A4 & $\mathbf{3}$ & $\mathbf{3}$ & $\mathbf{3}$ & $\mathbf{3}$ & $\mathbf{3}$ & $\mathbf{3}$ & $\mathbf{2}$ & $\mathbf{3}$ \\
\hline A5 & $\mathbf{7}$ & $\mathbf{7}$ & $\mathbf{7}$ & $\mathbf{7}$ & $\mathbf{6}$ & $\mathbf{7}$ & $\mathbf{5}$ & $\mathbf{7}$ \\
\hline A6 & $\mathbf{6}$ & $\mathbf{4}$ & $\mathbf{4}$ & $\mathbf{5}$ & $\mathbf{4}$ & $\mathbf{6}$ & $\mathbf{7}$ & $\mathbf{6}$ \\
\hline A7 & $\mathbf{5}$ & $\mathbf{6}$ & $\mathbf{6}$ & $\mathbf{6}$ & $\mathbf{7}$ & $\mathbf{5}$ & $\mathbf{6}$ & $\mathbf{5}$ \\
\hline
\end{tabular}

Step 2: Calculate Spearman rank correlation coefficient values using the formulas as described in Section 4.1. 
Table 16. Spearman Rank Correlation Coefficient Values

\begin{tabular}{|c|c|c|c|c|c|c|c|c|}
\hline & AHP & Copras & SAW & Topsis & FTopsis & $\begin{array}{c}\text { Promet } \\
\text { hee-2 }\end{array}$ & $\begin{array}{c}\text { Compromise } \\
\text { Programming }\end{array}$ & $\begin{array}{c}\text { Weighted } \\
\text { Avg }\end{array}$ \\
\hline AHP & $\mathbf{1}$ & 0.8929 & 0.8929 & 0.9643 & 0.8214 & 1.0000 & 0.7857 & 1.0000 \\
\hline Copras & 0.8929 & $\mathbf{1}$ & 1.0000 & 0.9643 & 0.9643 & 0.8929 & 0.6429 & 0.8929 \\
\hline SAW & 0.8929 & 1.0000 & 1 & 0.9643 & 0.9643 & 0.8929 & 0.6429 & 0.8929 \\
\hline Topsis & 0.9643 & 0.9643 & 0.9643 & $\mathbf{1}$ & 0.9286 & 0.9643 & 0.7500 & 0.9643 \\
\hline FTopsis & 0.8214 & 0.9643 & 0.9643 & 0.9286 & $\mathbf{1}$ & 0.8214 & 0.6786 & 0.8214 \\
\hline Promethee-2 & 1.0000 & 0.8929 & 0.8929 & 0.9643 & 0.8214 & $\mathbf{1}$ & 0.7857 & 1.0000 \\
\hline $\begin{array}{c}\text { Compromise } \\
\text { Programming }\end{array}$ & 0.7857 & 0.6429 & 0.6429 & 0.7500 & 0.6786 & 0.7857 & 1 & 0.7857 \\
\hline Weighted Avg & 1.0000 & 0.8929 & 0.8929 & 1.0000 & 0.8214 & 1.0000 & 0.7857 & $\mathbf{1}$ \\
\hline
\end{tabular}

Step 3: Again determine Spearman rank correlation coefficient values (after reorganization) using the formulas as described in Section 4.1.

\section{Table 17. Spearman Rank Correlation Coefficient Values}

\begin{tabular}{|c|c|c|c|c|}
\hline & SUM & $\begin{array}{c}\text { No of } \\
\text { considered } \\
\text { elements }\end{array}$ & AVG & RANK \\
\hline AHP & 6.3571 & 7 & 0.908 & $\mathbf{3}$ \\
\hline COPRAS & 6.2500 & 7 & 0.893 & $\mathbf{5}$ \\
\hline SAW & 6.2500 & 7 & 0.893 & $\mathbf{5}$ \\
\hline TOPSIS & 6.5000 & 7 & 0.929 & $\mathbf{1}$ \\
\hline FTOPSIS & 6.0000 & 7 & 0.857 & $\mathbf{7}$ \\
\hline PROMETHEE-2 & 6.3571 & 7 & 0.908 & $\mathbf{4}$ \\
\hline $\begin{array}{c}\text { COMPROMISE } \\
\text { PROGRAMMING }\end{array}$ & 5.0715 & 7 & 0.724 & $\mathbf{8}$ \\
\hline $\begin{array}{c}\text { WEIGHTED } \\
\text { AVG }\end{array}$ & 6.3928 & 7 & 0.913 & $\mathbf{2}$ \\
\hline
\end{tabular}

\section{Conclusion}

In this paper it is clear that the performance evaluation of non-teaching staff is a difficult and sensitive issue which has quantitative and qualitative aspects, complexity and imprecision. In this context, using eight methods we noticed from Table 15 that the final ranking of these methods slightly differs from each other; a group decision making method (Spearman Rank Correlation Method) is implemented to get a single ranking structure.

Each method has some advantages and disadvantages that affect the results of rating.

Advantages are-

- AHP is captured the decision maker's preferences, traditional AHP still cannot reflect the human thinking style.

- The approach COPRAS is intended to support the decision making process and increase the efficiency of there solution process.

- SAW clearly demonstrates the idea of integrating the values and weights of criteria into a single estimating value - the criterion of the method.

- In this study also there is no doubt from Table 17, it is observed that TOPSIS method quite capable and computationally easy to evaluate which gives more 
accurate result to select significant effect of stress from a given data than any other method.

- The transparency, objectivity and easy implementation nature of the fuzzy system makes their method easy to understand and enables experts to explain the results of the evaluation to skeptic non-teaching staffs.

- Fuzzy TOPSIS ranks alternatives measuring their relative distances to positive ideal solution and negative ideal solutions, providing then a meaningful performance measurement for each alternative.

- PROMETHEE-2 method is capable of accurately describing characteristics of criteria and analyzing the stability of solutions through changes in weights and parameters and presenting results of calculations.

- Compromise Programming approach is simple conceptual structure.

- The calculation of Weighted Average method is very easy.

Disadvantages are-

- The unfairness of results evaluating employee will lead to dissatisfaction of employee, which does not reach the organization's goal.

- To avoid the biased opinion on evaluating, the committee of evaluating should be chosen carefully. And the committee should have meticulous knowledge of the work and human resource management.

- Considering both the quantitative and qualitative evaluating criteria is very important because it can reduce lacking dimensions which employee is good at or not.

- Except for two extreme (i.e. when $\mathrm{p}=0$ and $\infty$ ) there is no clear interpretation of the various values of the parameter $p$. Therefore, the selection of 'best' non teaching staff within the reduced set of compromise alternatives must be made on a further insight into the compromise set of non-dominated alternatives.

Finally this study establishes a multi criteria decision making approach that integrates eight methods to analyze the performance of non-teaching staff which presents a great preference to the Education sector to increase their goodwill and maintains the tradition.

\section{References}

[1] H. D. Stoloviteh and J. E. Keeps, "Handbook of Human Performance Technology", San Franeiseo: Jossey-ass/Pfeiffer, (1999).

[2] M. Jafari, A. Bourouni and R. H. Amiri, "A New Framework for Selection of the Best Performance Appraisal Method", European Journal of Social Sciences, vol. 7, no. 3, (2009)

[3] C. Moon, J. Lee, C. Jeong, J. Lee, S. Park and S. Lim, "An Implementation Case for the Performance Appraisal and Promotion Ranking", IEEE International Conference on System, Man and Cybernetics, (2007).

[4] T. L. Saaty, "The Analytic Hierarchy Process", McGraw-Hill, New York, (1980).

[5] T. L. Saaty, "Priority Setting in Complex Problems", IEEE Transactions on Engineering Management, vol. 30, no. 3, (1983), pp. 140-155.

[6] C. L. Hwang, K. Yoon, "Multiple Attribute Decision Making Methods and Applications", Springer, Berlin Heidelberg, (1981).

[7] K. Oraee and E. Bakhtavar, "Selection of Tunnel Support System by Using Multi Criteria DecisionMaking Tools", 29th International Conference on Ground Control in Mining.

[8] M. A. Abo-Sinna and A. H. Amer, "Extensions of TOPSIS for multi-objective large-scale nonlinear programming problems", Applied Mathematics and Computation, vol. 162, (2005), pp. 243-256.

[9] G. R. Jahanshahloo, F. HosseinzadehLotfi and M. Izadikhah, "An algorithmic method to extend TOPSIS for decision-making problems with interval data", Applied Mathematics and Computation, (2005). 
[10] P. Kumar Dey, S. Chattaraj and D. Nath Ghosh, "Faculty Selection in Engineering Organization using AHP \& TOPSIS", International Journal of Information and Computing Science (IJICS) 06/2012; vol. 15, no. 1, (2012).

[11] L. Z. Zadeh, "Fuzzy sets. Inf. Control", vol. 8, (1965), pp. 338-353.

[12] D. Chatterjee and B. Mukherjee, "Study of Fuzzy-AHP Model To Search The Criterion In the Evaluation Of The Best Technical Institutions: A Case Study", International Journal of Engineering Science and Technology, vol. 2, no. 7, (2010), pp. 2499-2510.

[13] H. J. Zimmermann, "Fuzzy set theory and its applications", Kluwer, Boston, (1992).

[14] G. Bojadziev and M. Bojadziev, "Fuzzy sets and fuzzy logic applications", World Scientific, Singapore, (1998).

[15] P.-C. Chen, "A Fuzzy Multiple Criteria Decision Making Model in Employment Recruitment", IJCSNS International Journal of Computer Science and Network Security, vol. 9, no. 7, (2009) July, pp. 113-117.

[16] A. I. Olcer and A. T. Odabasi, "A new fuzzy multiple attributive group decision making methodology and its application to population/maneuvering system selection problem", European Journal of Operational Research, vol. 166, no. 1, pp. 93-114, (2005).

[17] G. S. Liang, "Fuzzy MCDM based on ideal and anti-ideal concepts", Eur J Oper Res., vol. 112, (1999), pp. 682-691.

[18] E. Triantaphyllou and C. T. Lin, "Development and evaluation of five fuzzy multiattribute decisionmaking methods", Int J Approx Reason, vol. 14, (1996), pp. 281-310.

[19] M. F. A. Taleb and B. Mareschal, "Water Resources Planning in the Middle East: Application of the PROMETHEE V Multicriteria Method”, European Journal of Operational Research, vol. 81, (1995), pp. 500-511.

[20] J. Ch. Pomerol and S. B. Romero, "Multicriterion Decision in Management: Principles and Practice", Kluwer Academic, Netherlands, (2000).

[21] J. P. Brans, Ph. Vincke and B. Mareschal, "How to Select and How to Rank Projects: The PROMETHEE method", European Journal of Operational Research, vol. 24, (1986), pp. 228-238.

[22] C. Spearman, "The Proof and Management of Association Between Two Things", American Journal of Psychology, vol. 15, (1904), pp. 72-101.

[23] G. Woodbury, "Introduction to Statistics", Thomson Learning, USA, (2002).

[24] K. S. Raju and D. Nagesh Kumar, "Multi-criterion Decision-Making in Irrigation Planning", Agricultural Systems, vol. 62, no. 2, (1999), pp. 117-129.

[25] P. H. Liu and C. C. Wei, "A Group Decision-Making Method for Appraising the Performance of Organizations", International Journal of the Computer, the Internet and Management, vol. 8, no. 2, (2000), pp. 39-49

\section{Authors}

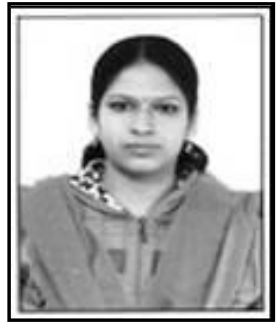

Sukarna Dey (D.O.B.: $7^{\text {th }}$ October, 1985) is currently Assistant, Professor in the the Department of Mathematics of Dr.B.C.Roy, Engineering College,Durgapur,West Bengal, India. She obtained B.Sc (Mathematics) from the University of Burdwan, Burdwan, India in the year of 2007 and M.Sc Sc in Mathematics, from the same university in the year 2009. She has over 05, years of teaching experience and 01 year of research experience.

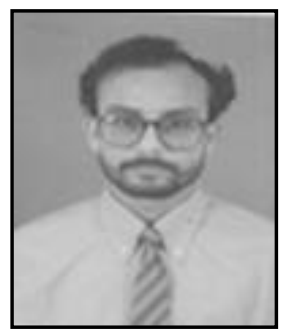

Dr. Dipendra Nath Ghosh (D.O.B.:1st April, 1976) is currently Associate Professor in the Department of Mathematics of Dr.B.C.Roy Engineering College, Durgapur, West Bengal, India . He got his Masters in Mathematics from the University of Burdwan, Burdwan, India in the year 1999 .He obtained his M.C.A. degree from the same university in the year 2003 his Ph.D. award from the Department of Computer Science, the University of Burdwan, Burdwan, India in the year 2008. He has altogether nine years of teaching and six years of research experience. He has fifteen publications in different reputed journals. His areas areas of research interest are Time Series Analysis, Fuzzy Logic and Decision Theory. 